\title{
The calculus of telescopic urbanism
}

\section{Pushpa Arabindoo}

Developing Amin's invocation of a telescopic urbanism as more than a visual metaphor, this paper seeks to rethink its epistemological and methodological focus, resisting at the same time the tendency to oversimplify the relationship between the different optics be outlines. Threatened by a dominant meta-narrative of a numerically driven calculus, this paper identifies an opportunity in Amin's telescopic urbanism to reject the 'big-data' approach to the city. In this context, it challenges the narrow assumptions about planetary urbanization rooted in a quantitative veneer and a statistical dependency that is arbitrary and abistorical. Moving beyond our current obsession with the ethos of enumeration, it identifies the need for a situated knowledge that accommodates the statistical alongside the anecdotal outlining not just a thesis on the urban poor but also rethinking the episteme of the city as a machine for learning.

Key words: India, Slum Census 2011, urban poverty, ethnography of enumeration

'India's Slumdog census reveals poor conditions for one in six urban dwellers.' (The Guardian, 22 March 2013) (1,2 $^{1}$

'Census shockers: Imagine all of France in slums and US sans power.' (The New Indian Express, 24 March 2013)

$\mathrm{E}$ arlier this year, the office of the Registrar General and Census Commissioner, India released its findings from the much-awaited 'slum census', conducted as part of the national 2011 Census. While most international and local press assumed an uncompromising view of the fact that $17.5 \%$ of urban India, that is, 64 million are living in slums, for the Ministry of Housing and Urban Poverty Alleviation, this was a relief given that the 2010 projection of 93 million would have indicated a considerably higher $27.5 \%$. Ignoring the need for a more careful and detailed analysis of what such numbers mean, specifically in terms of their rigour and reliability, state officials failed to realise that the decrease from earlier estimates does not necessarily suggest the success of government schemes in eradicating or improving slums but might be due to the spate of massive slum evictions that have taken place in the millennial decade, revealing worryingly an increasingly exclusionary nature of the urban process. There is also the fact that, as a Ministry representative confessed, 'state governments are unwilling to admit to there being more slums in their cities because then they will have to provide these slums basic services like water and drainage'. ${ }^{3}$ And yet, state machinery is being deployed at an unprecedented scale to create a proprietary database that involves not just the enumeration of slums but also the more challenging initiative of counting the urban poor through the even more contested Below Poverty Line (BPL) Census. 
While such exercises are justified through the need for an empirical reality that is seemingly objective, they have not been without controversy. Questions have been raised over the fact that such data are often arbitrary and ahistorical, and therefore prone to manipulation through subjective interpretation. There has also been the larger question of generating poverty and slum statistics based on an efficient drawing of a single line, and working out the number of the unfortunate ones finding themselves below or inside it. Irrespective of the fact that one has to define a threshold at some point, where and how it is done has generated a heated discussion, as a result of which recent debates around urban poverty have unfortunately been confined to methodological rather than conceptual concerns.

Reservations about the coercive nature of the larger Census-based process notwithstanding, what is of greater concern is the fact that exercises such as the slum census are being justified on the basis of the Indian government's commitment to the UNHabitat's millennial agenda of making 'cities without slums', placing considerable emphasis on quantitative methodologies and an exceptional desire to capture the urban poor and their environments as a tangible, measurable entity. The result is not just a gross oversimplification of the relationship between urban poverty and slums, but also a deeper concern about the obsession of international financial institutions such as the United Nations (UN) and the World Bank with hard data-sets. Their influence in the global poverty and development debates has compelled aid-dependent nations to generate reams of poverty statistics, hardly questioning the crude standardised formulas that are often applied. In a scathing review of UN-Habitat's Challenge of the Slums report, Gilbert (2005) questions such reports prepared by international agencies, and the necessity to calculate the number of 'slum-dwellers' when it draws attention to the problem but the solutions it offers are often simple remedies that are either bland or miss the point. It is thus difficult to place much faith in the resulting blanket policies and dictums which seem misguided in their narrow assumptions about solving poverty. The supposedly rational empirical dynamism attached to the ethos of enumeration leaves little room for a more nuanced understanding of the highly uneven historical-geographical transformations unfolding in cities today. Instead, as Brenner and Schmid (forthcoming) remind us in their critique of urban demography, statistical calculations impose a falsely constructed and tightly circumscribed static understanding of cities that is not only empirically untenable but also theoretically incoherent.

It is this meta-narrative of a numerically driven calculus that threatens Amin's telescopic urbanism where, irrespective of whichever end you look from, whether it is blurry or focused, seen in parts or whole, the duplicity of numbers dominates the view frame. This is something he is well aware of as, in a freewheeling conversation with Matthew Gandy, he explains his reservation about the prevalent orthodoxy in urban analysis that 'the contemporary city-with all its complexities, flows, continual changes, unexpected combinations and large-scale phenomenon-can be data captured' or what he deems is the 'big-data' approach to the city (Amin 2013a, 90). He finds it conceited 'to think that the availability of sophisticated mathematical models able to work large data in nuanced ways, allows the city to be visualised and understood in all its complexities and evolving changes' (90). While he frames his concern mainly as a methodological issue, Brenner and Schmid (forthcoming) contend that there is an intractable theoretical problem hidden behind 'false evidence' produced from a data-based approach to urban research. This is where the opportunity and challenge lies for telescopic urbanism to move beyond our current obsession with enumerating cities, and instead construct a more useful epistemology that can address effectively the current condition of capitalist, socio-spatial restructuring. 
This, however, does not necessarily mean a complete rejection of enumeration as an inappropriate heuristic device. For while questions persist about the arbitrary nature of its classifications and its strange ways of making the invisible not only visible but also vulnerable, it cannot be denied that the attendant practices of enumeration and its knowledge systems have been used in the empowerment of slum-dwellers and urban poor. Thus, even though, Amin (2013b) finds that his human potential optic has no particular care for audit by numbers, or the statistics of absolute and relative poverty, and is perhaps better served by complex ethnographies that refuse to reduce to the language of abjection, self-enumeration as pursued by the poor communities has been known to mobilise knowledge in a manner that enables them to resist eviction, and advance their own rights, resources and claims. This is something Appadurai (2012a, 2012b), despite his criticism of censuses as instruments of state power and control, admits to as he recognises that selfenumeration and self-mapping are more than tools for outlining social reality, and are in fact catalysts for group formation, developing a sense of community that did not exist until documentation. While it might make sense for an in-focus telescopic urbanism to not entirely shed its numerical tendencies and use a discourse of statistical reason commonsensically to convey situated knowledges about everyday practices, we still need to devise more meaningful ways of data collection ensuring that the resulting numbers are rooted in a clear theoretical reflexivity and do not lead us back to the strangely indeterminate quantitative terrain filled with empty abstractions. It is here that telescopic urbanism with its constant zooming in and out can be helpful as it has the unique opportunity of producing an urban calculus where numbers can be usefully disaggregated in detail at different socio-spatial scales without being fetishised.

What would also be helpful is to take Amin's (2013b) roughly laid out manifesto forward into a science of telescopic urbanism that not only accommodates at a methodological level the statistical alongside the anecdotal, but also epistemologically redefine the city as a machine for learning (McFarlane 2011) to create a new field that is not caught in the trap of what many scholars have now come to consider rather derisively as the 'urban age' discourse (Gleeson 2012; Brenner and Schmid, forthcoming). Amin's (2013b) outlining of the two urbanisms, that is, the business consultancy and human potential city, is a useful starting point, as we ask whether there are in reality such harshly drawn boundaries between one that is governed by an economic calculus, and the other by the cultural presumptions and habits of non-market behaviour. Rather than the concessionary urbanism that Amin (2013b) conjures up between the authorising city and the survivalist city, lived experiences show that while the conditions of these two urbanisms might be dispersed and highly differentiated, they are nevertheless linked together through overt and covert webs of connectivity. Thus, in several Indian cities, civil society and political society activists find themselves sometimes in uneasy alliances to battle the state over certain high-profile urban development projects, while at other times they return promptly to their own camps (Figures 1-3). This changing dynamic is something McFarlane (2012) explores through the ongoing debate on entrepreneurial urbanism as he finds that contemporary entrepreneurial strategies are increasingly co-produced bringing together ostensibly distinct actors over a shared terrain to the point that all divisions seem untenable. It is this shared ideology between business and slum entrepreneurialism, however uneasy it may seem with one driven by survival and the other by profit, that prompts the urban poor to belie the logic of 'deserving' citizens or resisting subjects where, instead of mobilising against displacement, they decide to negotiate better terms of redevelopment (Anand and Radamacher 2011). 
In this context, there is an element of naivety to the third optic Amin (2013b, 472) traces as 'one that registers the topographical coalitions and connections across and beyond the city, the communal energies and commitments, the agonistic relations between the subaltern and the state out of which the right of the poor to the city is claimed'. It is difficult to share his enthusiasm for the city of collective rights he envisions, one that is especially drawn from the UN Declaration of Human Rights, and in whose universalism he places much faith. First of all, at least where the right to the city debate is concerned, the UN has single-handedly hijacked the discourse out of its Lefebvrian comfort zone and transformed it into a catchy policy slogan, one that is nothing more than an empty signifier (cf. Merrifield 2011). Secondly, going down

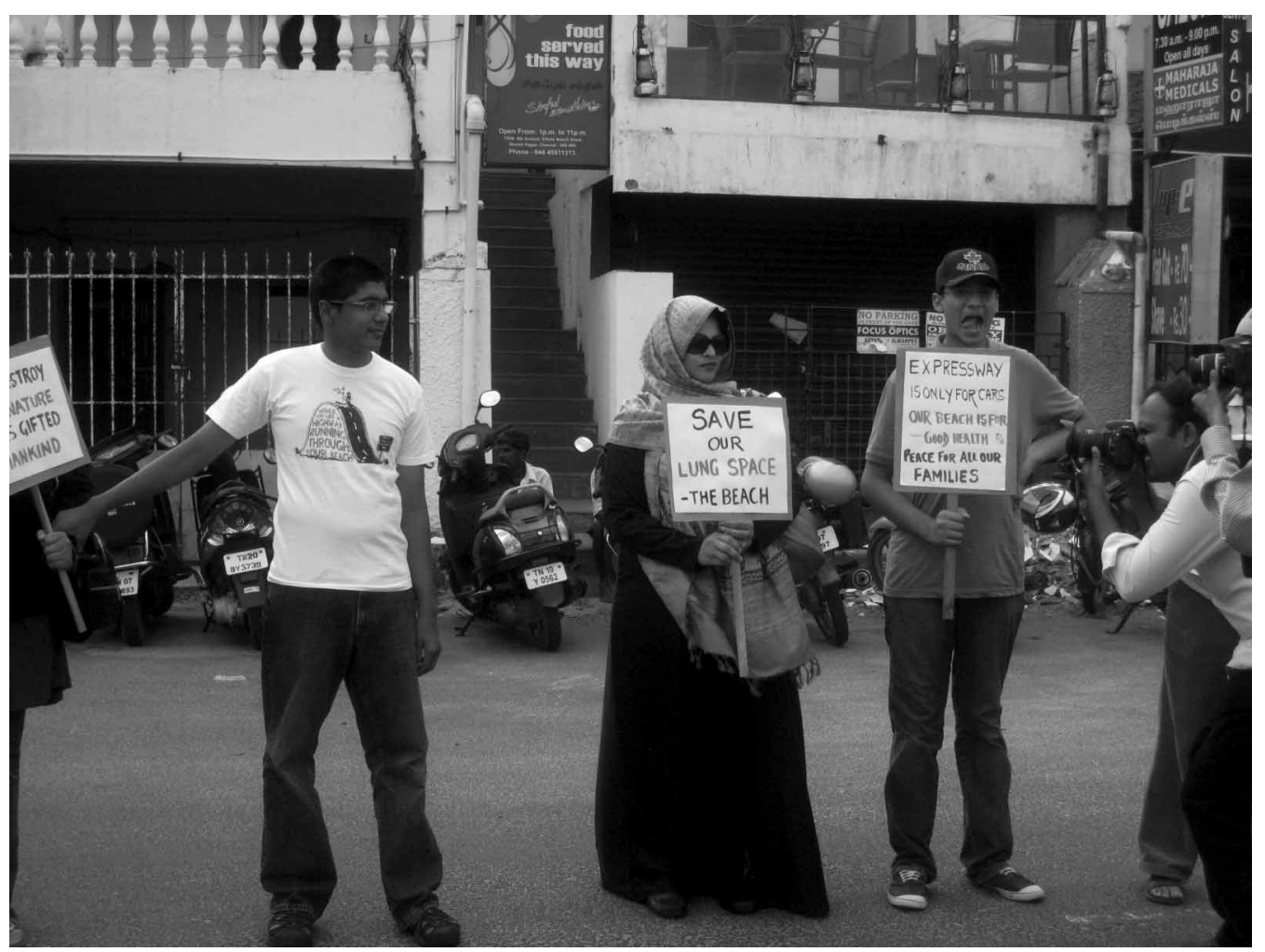

Figures 1-3 On 31 July 2010, members of 14 fishing hamlets (kuppams) under the banner of Meenavar Vaazhvurimai Paadhukaapu Kuzhu (Fisherfolk Livelihoods Rights Protection Committee) gathered at the popular Elliots Beach in Chennai to protest against the proposed $9.7 \mathrm{~km}$ elevated expressway along the eastern coast of Chennai, threatening them with eviction and relocation (Figure 1). They were joined by a strong contingent of middle-class residents who had mostly collected under the rubric of the 'Save Chennai's beaches' campaign. Drawing mostly on environmental concerns related to the protection of the beach as the city's critical lung space and the threat that such a project posed to Olive Ridley turtles, their English banners contrasted starkly with those of the fisherfolk who were pressing on a simpler yet more urgent need to preserve their homes and livelihoods (and written in Tamil) (Figure 2). While the demonstration tried to reframe the interactions between civil and political society activists as one of a comfortable collusion between two unlikely sets of actors, there was an undercurrent of tension that could not be denied. It was not just in the 'mob-like' behaviour of fishermen and women rallying together as an angry crowd against the more disciplined human-chain formation of middle-class protesters, but also in the way the notion of a possibly shared ideology became quickly absurd as, towards the end of the afternoon, fisherwomen were seen uncomfortably holding English placards displaying a bourgeois understanding of nature, one that they could little relate to (Figure 3) (Photos: Author, Chennai, India, 2010) 
CITY Vol. 17, No. 4

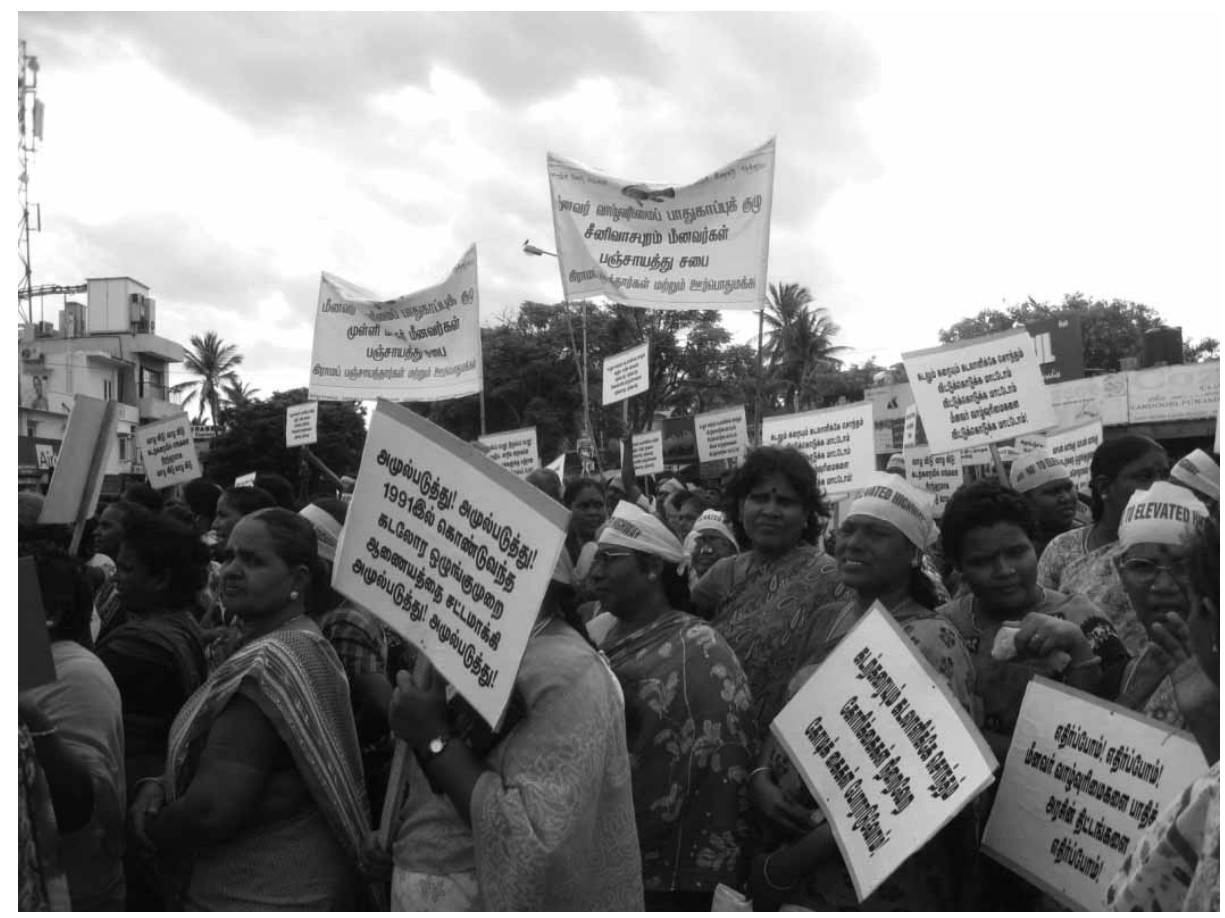

Figure 2

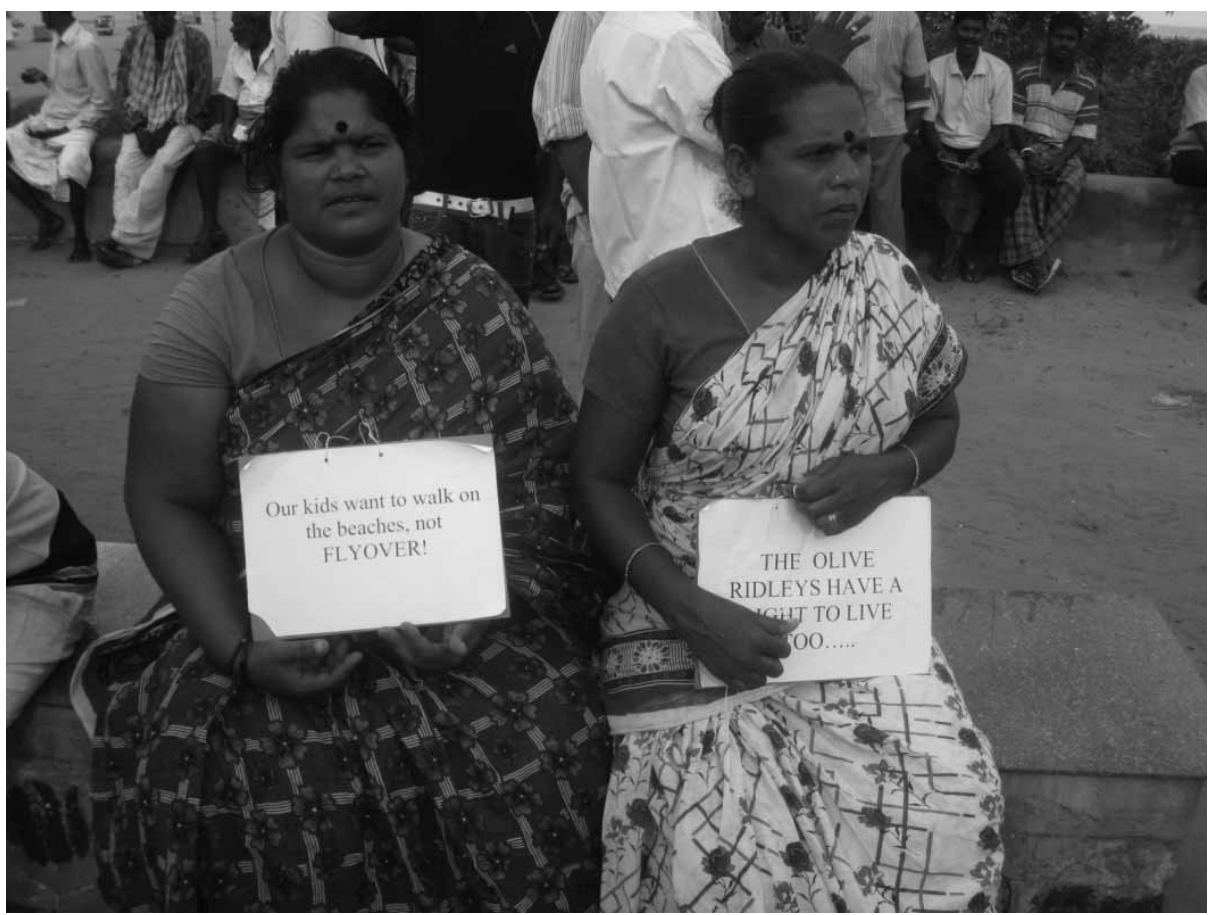

Figure 3 
the UN kind of rights-based discourse has triggered a shift in emphasis from equality as a core social problem of urbanisation to the goal of achieving a general urban state of 'inclusion'. Its agenda for inclusive cities thus ends up institutionalising other forms of exclusion and inequality allowing it to become entrenched within the current scenario of urban development (Anand and Radamacher 2011).

Although Amin (2013a) outlines his telescopic urbanism as mainly a visual metaphor, it has the ability to force a thesis on the urban poor that is not framed in just a representational way but through an ethnography of numbers that calls into question the current set of urban epistemes in place. It may seem ingenuous to believe that a refocused telescopic urbanism can tell the whole story when it seems that our urban experiences will always be partial and multiple. Nevertheless, Amin's (2013b) optics present several cues which takes us as close to this task as possible, highlighting several ways of seeing the city simultaneously and in juxtaposition. What it also sets up and perhaps can benefit from is a more substantive learning structure that through the inculcation of facts, rules, ideas or policy documents goes beyond a visual optic to present an alternative set of urban knowledges, imaginaries, logics and practices that entail knowing and learning the city in an entirely different way.

\section{Notes}

1 M. Rahman, 'India's Slumdog Census Reveals Poor Conditions for One in Six Urban Dwellers.' The Guardian, March 22, 2013. Accessed April 10, 2013. http://www.guardian.co.uk/world/2013/ mar/22/india-slumdog-census-poor-conditions
2 S. Aiyyar, 'Census Shockers: Imagine All of France in Slums and US sans Power.' The New Indian Express, March 24, 2013. Accessed April 10, 2013. http:// newindianexpress.com/opinion/article 1514260.ece

3 R. Shrinivasan, '17\% of Urban India Lives in Slums: Census.' The Times of India, March 22, 2013. Accessed April 10, 2013. http://articles. timesofindia.indiatimes.com/2013-03-22/india/ 37936264_1_slum-population-slum-householdsrajiv-awas-yojana

\section{References}

Amin, A. 2013a. "The Scopic Regimes of Urban Neglect.' Interview by Matthew Gandy." Cityscapes 03 (Summer): 86-99.

Amin, A. 2013b. "Telescopic Urbanism and the Urban Poor." City 17 (4): 476-492.

Anand, N., and A. Radamacher. 2011. "Housing in the Urban Age: Inequality and Aspiration in Mumbai." Antipode 43 (5): 1748-1772.

Appadurai, A. 2012a. "The Spirit of Calculation." Cambridge Anthropology 30 (1): 3-17.

Appadurai, A. 2012b. "Why Enumeration Counts." Environment and Urbanization 24 (2): 639-641.

Brenner, N., and C. Schmid.. Forthcoming. "The Urban Age in Question". International Journal of Urban and Regional Research.

Gilbert, A. 2005. "Book Review: The Challenge of Slums: Global Report on Human Settlements 2003." Progress in Human Geography 29 (1): 118-120.

Gleeson, B. 2012. "The Urban Age: Paradox and Prospects." Urban Studies 40 (5): 931-943.

McFarlane, C. 2011 . "The City as a Machine for Learning." Transactions of the Institute of British Geographers 36 (3): 360-376.

McFarlane, C. 2012. "The Entrepreneurial Slum: Civil Society, Mobility and the Co-production of Urban Development." Urban Studies 49 (13): 2795-2816.

Merrifield, A. 2011. "The Right to the City and Beyond." City 15 (3-4): 473-481.

Pushpa Arabindoo, Department of Geography, University College London. Email: p.arabindoo@ucl.ac.uk 